\title{
Preparation of silicon nitride-barium aluminum silicate composites by freeze gelation
}

\author{
Juanli Yu ${ }^{\mathrm{a}, *}$, Sen $\mathrm{Li}^{\mathrm{b}}$, Yi Lv ${ }^{\mathrm{a}}$, Yingmin Zhao ${ }^{\mathrm{a}}$, Yuchen Pei ${ }^{\mathrm{a}}$ \\ ${ }^{a}$ Research Institute of Aerospace Special Materials and Technology, Beijing 100074, China \\ b State Key Laboratory of High Temperature Gas Dynamics, Institute of Mechanics, Chinese Academy of Sciences, Beijing 100190, China
}

\section{A R T I C L E I N F O}

\section{Article history:}

Received 1 November 2014

Accepted 24 January 2015

Available online 3 February 2015

Keywords:

Silica sol

$\mathrm{Si}_{3} \mathrm{~N}_{4} / \mathrm{BAS}$

Freeze gelation

Colloidal processing

Ceramic composites

\begin{abstract}
A B S T R A C T
An effective approach to prepare silicon nitride-barium aluminum silicate ( $\mathrm{Si}_{3} \mathrm{~N}_{4} / \mathrm{BAS}$ ) composites by freeze gelation was described. Utilizing the gelation of particulate silica sol by freezing to solidify ceramic slurry, in the forming and drying process, the cracking and warpage of green body were avoided, and the shrinkage rate was $0.6 \%$. The added barium oxide and alumina absorbed silica in sol to prepare $\mathrm{Si}_{3} \mathrm{~N}_{4} / \mathrm{BAS}$ glass ceramic matrix composites, and the flexural strength, work of fracture and density of $\mathrm{Si}_{3} \mathrm{~N}_{4} / \mathrm{BAS}$ composites were $342 \mathrm{MPa}, 181 \mathrm{~J} / \mathrm{m}^{2}$ and $3.0 \mathrm{~g} / \mathrm{cm}^{3}$, respectively.
\end{abstract}

(c) 2015 Elsevier B.V. All rights reserved.

\section{Introduction}

Silicon nitride $\left(\mathrm{Si}_{3} \mathrm{~N}_{4}\right)$ has excellent mechanical, physical and chemical properties, and it is a promising wave-transparent radome materials used at high temperature environment generated by high supersonic and hypersonic speeds [1]. However, the densification of $\mathrm{Si}_{3} \mathrm{~N}_{4}$ has to rely on sintering additives because of its highly covalent bond character. At present, many oxides used as sintering additives $\left(\mathrm{MgO}, \mathrm{Al}_{2} \mathrm{O}_{3}, \mathrm{Y}_{2} \mathrm{O}_{3}, \mathrm{Yb}_{2} \mathrm{O}_{3}\right.$, etc.) with low melting temperature degrade the high-temperature sintering properties of $\mathrm{Si}_{3} \mathrm{~N}_{4}$ ceramics. Barium aluminum silicate (BAS) is one of the glass ceramic materials with high melting temperature $\left(1760^{\circ} \mathrm{C}\right)[2]$, BAS used as sintering additive is promising to prepare $\mathrm{Si}_{3} \mathrm{~N}_{4}$ with excellent high-temperature mechanical properties.

Ceramics forming is the key process in the preparation of high performance ceramics. Freeze gelation is an innovative ceramics forming technique, and it is based on a synthesis of ideas borrowed from traditional sol-gel and freeze-casting, which is near net-shape forming with low cost and short production time due to the quick and easy dry of green body without cracking and apparent shrinkage [3]. In the freeze gelation, the particulate colloidal silica based sol is gelated by freezing, not by conventional means (altering the sol $\mathrm{pH}$ ), to solidify ceramic slurry $[3,4]$, the range of freezing temperature can be from -60 to $-196{ }^{\circ} \mathrm{C}$. So far, little work has been focused on the preparation of $\mathrm{BAS} / \mathrm{Si}_{3} \mathrm{~N}_{4}$ composites by freeze gelation $[5,6]$. In the study, the preparation of $\mathrm{BAS} / \mathrm{Si}_{3} \mathrm{~N}_{4}$ composites by freeze gelation is

\footnotetext{
* Corresponding author. Tel.: +86 15901213777.

E-mail address: yujuanlli@126.com (J. Yu).
}

investigated. The added barium oxide and alumina absorb silica in sol, then the formed $\mathrm{BaO}-\mathrm{Al}_{2} \mathrm{O}_{3}-2 \mathrm{SiO}_{2}$ system is used as sintering aid for nitride silicon, $\mathrm{Si}_{3} \mathrm{~N}_{4} / \mathrm{BAS}$ glass ceramic matrix composites are finally formed by sintering, and the performances are characterized.

\section{Materials and method}

The preparation of $\mathrm{Si}_{3} \mathrm{~N}_{4}$ /BAS glass ceramic matrix composites by freeze gelation includes the following processes: slurry preparation, freeze gelation, drying, and sintering. The particle size distribution of $\mathrm{Si}_{3} \mathrm{~N}_{4}$ powders was determined with a Malvern particle analyzer, and the mean particle size (D50) of $\mathrm{Si}_{3} \mathrm{~N}_{4}$ powders ( $\alpha$ phase $>94 \%$ ) was $0.53 \pm 0.04 \mu \mathrm{m}$ (see Fig. $1 \mathrm{~A}$ ). In the preparation process of slurry, the average particle size of $\mathrm{SiO}_{2}$ was $20 \mathrm{~nm}$ in water borne silica sol, the mean particle size (D50) of $\mathrm{Al}_{2} \mathrm{O}_{3}$ (99.9\% purity) was $0.7 \pm 0.06 \mu \mathrm{m}$, and $\mathrm{Si}_{3} \mathrm{~N}_{4}, \mathrm{Al}_{2} \mathrm{O}_{3}, \mathrm{BaO}$ and water borne silica sol employed in the experiment were all commercially available materials. According to the stoichiometry of $\mathrm{BaO}-\mathrm{Al}_{2} \mathrm{O}_{3}-2 \mathrm{SiO}_{2}$ (BAS), $\mathrm{Al}_{2} \mathrm{O}_{3}$ and $\mathrm{BaO}$ were added on the basis of the content of $\mathrm{SiO}_{2}$ in silica sol, and the mass ratio of $\mathrm{Si}_{3} \mathrm{~N}_{4}$ powders to BAS was 7:3; the solid loading $\left(\mathrm{Si}_{3} \mathrm{~N}_{4}, \mathrm{Al}_{2} \mathrm{O}_{3}, \mathrm{BaO}\right.$ and nanoscale $\left.\mathrm{SiO}_{2}\right)$ was $71 \mathrm{wt} \%$; $1 \mathrm{wt} \%$ ammonium salt of poly (acrylic acid) used as dispersant was added to minimize the agglomeration. The mixture was rolled by using agate balls for $8 \mathrm{~h}$ in polyethylene bottles. The fluidity of slurry was similar to toothpaste, and the slurry viscosity was shown in Fig. 1B. The slurry was filled into mold, and the mold was vibrated for $10 \mathrm{~min}$ for degasification and then kept in liquid nitrogen for $0.5 \mathrm{~h}$ to freeze and age the slurry. In the process of freeze, sol-gel reaction occurred, the solvent transformed into solid phase, and the 

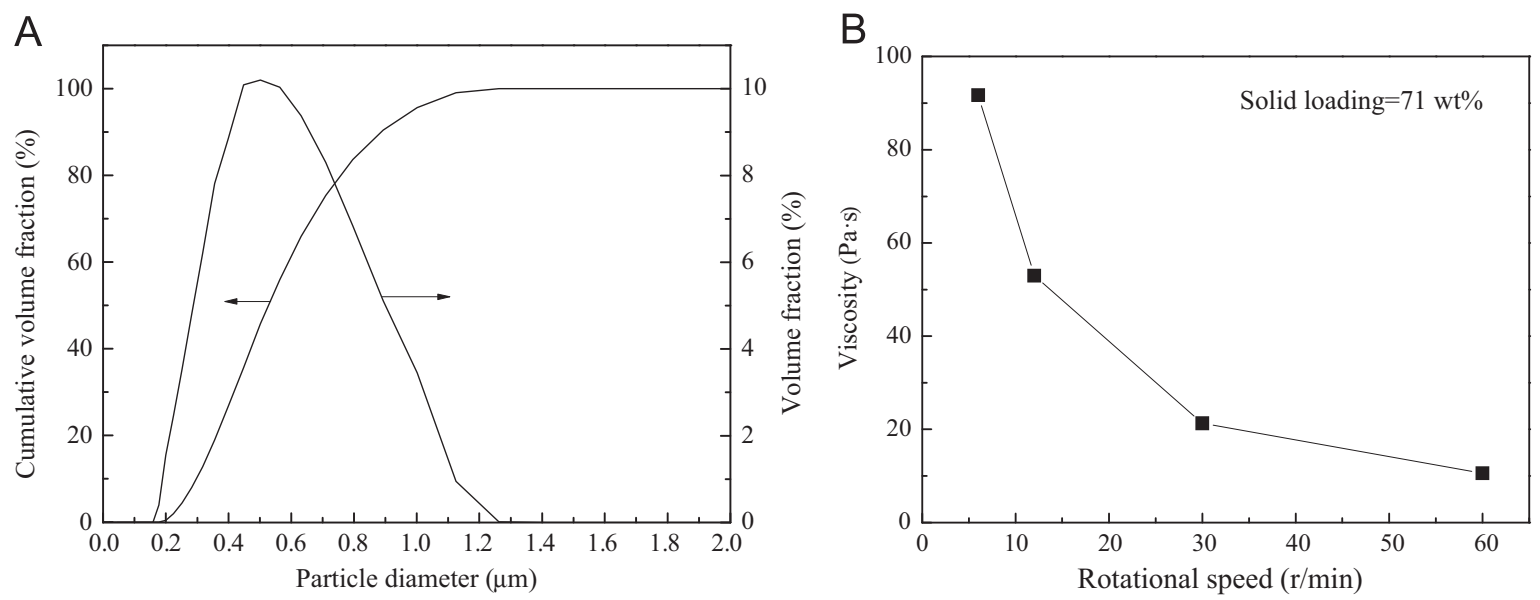

Fig. 1. $\mathrm{Si}_{3} \mathrm{~N}_{4}$ particle size distribution (A) and slurry viscosity (B).
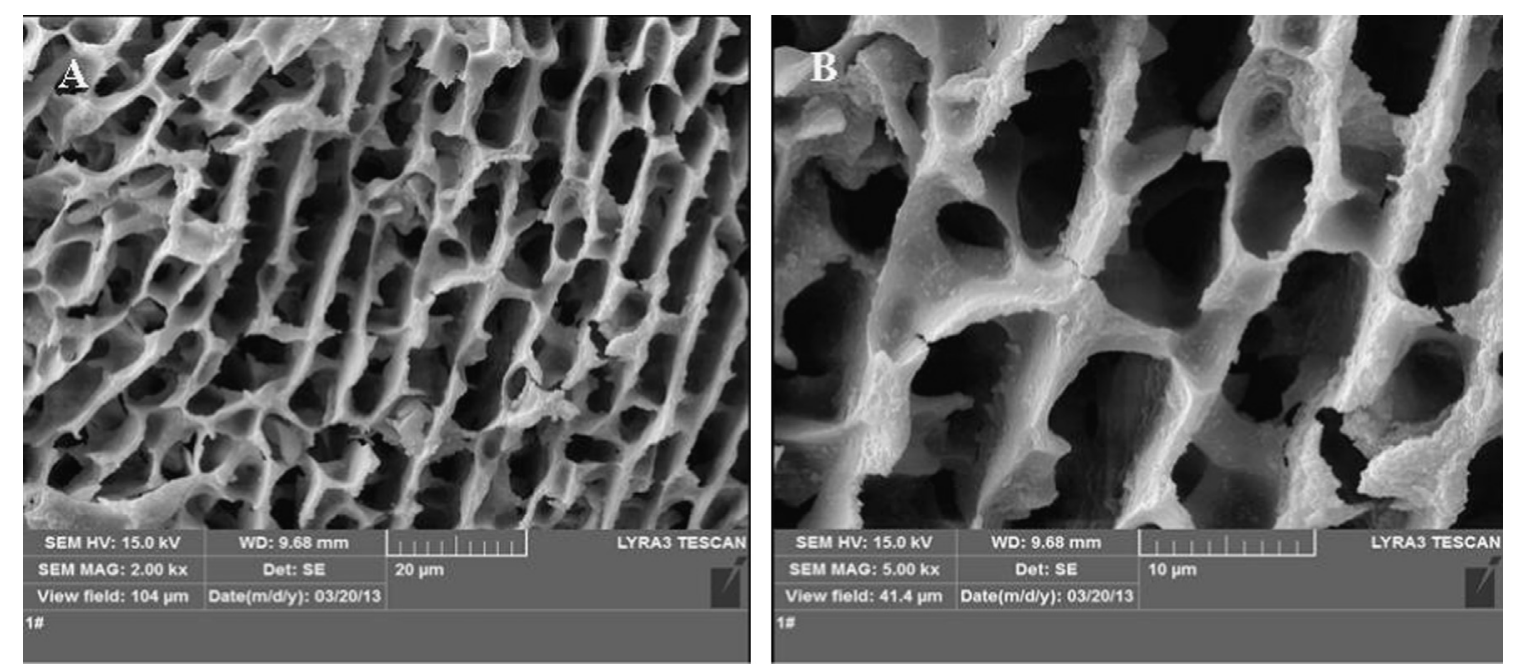

Fig. 2. Three-dimensional network of silica gel.

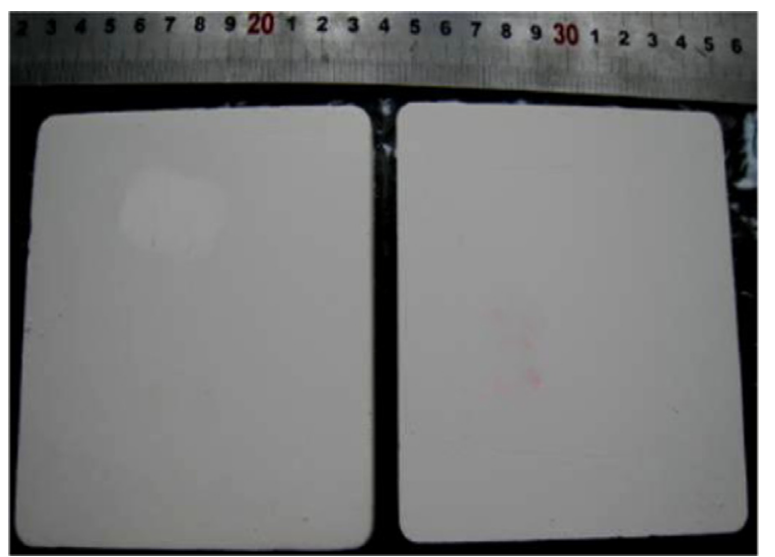

Fig. 3. Dried green bodies of $\mathrm{Si}_{3} \mathrm{~N}_{4} / \mathrm{BAS}$ composites by freeze gelation. (For interpretation of the references to color in this figure legend, the reader is referred to the web version of this article.)

formed gel held the filler powder together. The frozen demolded sample was dried in a furnace at $3{ }^{\circ} \mathrm{C} /$ min heating rate and kept for $4 \mathrm{~h}$ at $100{ }^{\circ} \mathrm{C}$ to make the sample dry completely. The dried green body was sintered at $5{ }^{\circ} \mathrm{C} / \mathrm{min}$ heating rate and kept for $2.5 \mathrm{~h}$ at

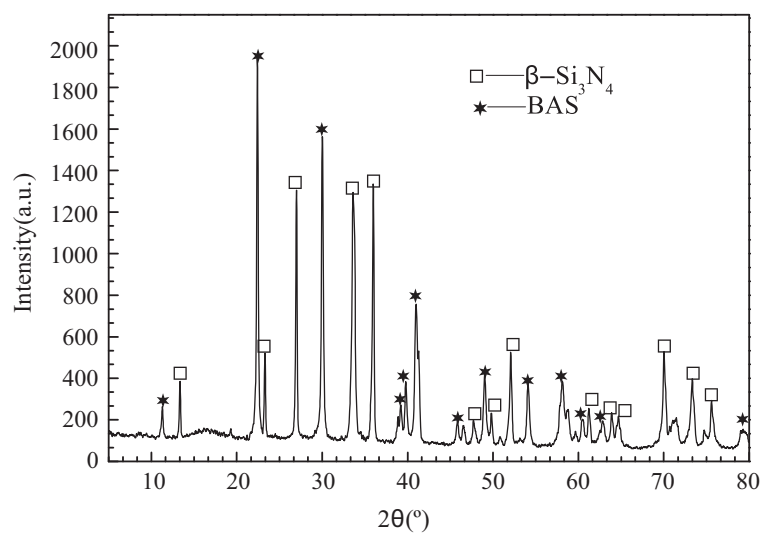

Fig. 4. XRD patterns of $\mathrm{Si}_{3} \mathrm{~N}_{4} / \mathrm{BAS}$ composites (the ratio of $\mathrm{Si}_{3} \mathrm{~N}_{4}$ to $\mathrm{BAS}$ is $7: 3$, and sample is sintered at $1780{ }^{\circ} \mathrm{C}$ for $2.5 \mathrm{~h}$ ).

$1780{ }^{\circ} \mathrm{C}$, and $\mathrm{Si}_{3} \mathrm{~N}_{4} / \mathrm{BAS}$ glass ceramic matrix composites were finally obtained. 

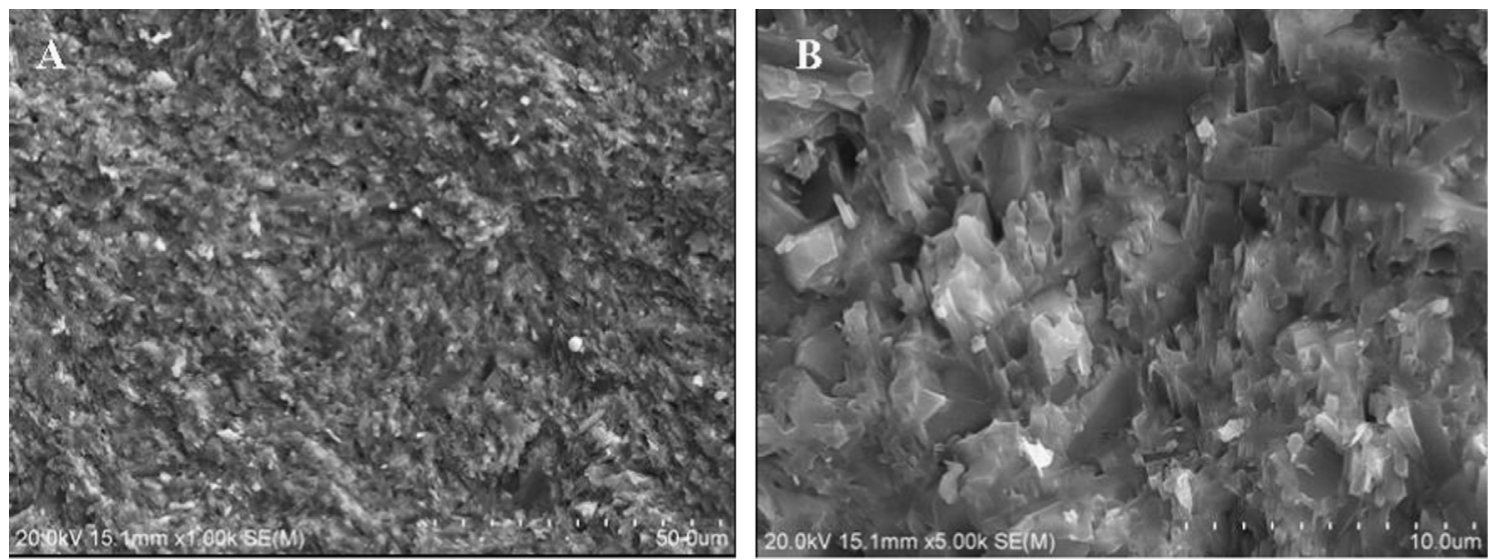

Fig. 5. Fracture surface micrograph of $\mathrm{Si}_{3} \mathrm{~N}_{4} / \mathrm{BAS}$ composites (the ratio of $\mathrm{Si}_{3} \mathrm{~N}_{4}$ to BAS is $7: 3$, and sample is sintered at $1780{ }^{\circ} \mathrm{C}$ for $2.5 \mathrm{~h}$ ).

\section{Results and discussion}

Pure sol is transformed into gel by freezing, and the uniform network structure of silica gel is obtained (see Fig. 2). In the preparation of $\mathrm{Si}_{3} \mathrm{~N}_{4} / \mathrm{BAS}$ composites by freeze gelation, the silica particles with hydroxyl groups on the surfaces are rejected away from the solidifying interface and forced into the interstices between the ice crystals when silica sol is froze, the polycondensation reaction occurs when these hydroxyl groups approach to each other (see R1), then the particulate colloidal silica based sol is gelated by freezing to form three-dimensional network of silica gel, and ceramic powder particles are finally wrapped in the network of reactions and $\alpha-\mathrm{Si}_{3} \mathrm{~N}_{4}$ is completely transformed into $\beta-\mathrm{Si}_{3} \mathrm{~N}_{4}$. Fig. 5 shows the typical fracture surface micrograph of $\mathrm{Si}_{3} \mathrm{~N}_{4} / \mathrm{BAS}$ composites, it indicates that the microstructure of $\mathrm{Si}_{3} \mathrm{~N}_{4} / \mathrm{BAS}$ composites is uniform (see Fig. $5 \mathrm{~A}$ ), rod-shaped $\beta$ - $\mathrm{Si}_{3} \mathrm{~N}_{4}$ grains are oriented randomly in a continuous BAS matrix (see Fig. 5B), and the features of whisker pullout, debonding and bridging are exhibited which are known as toughening mechanisms for brittle materials. The flexural strength, work of fracture and density of $\mathrm{Si}_{3} \mathrm{~N}_{4} / \mathrm{BAS}$ composites are $342 \mathrm{MPa}, 181 \mathrm{~J} / \mathrm{m}^{2}$ and $3.0 \mathrm{~g} / \mathrm{cm}^{3}$, respectively.<smiles>C[Si](C)(C)O[Si](C)(C)CC[Si](C)(C)O[Si](C)(C)[18OH]</smiles>

silica gel to achieve in-situ forming of ceramic slurry. Due to the very strong bonds formed between silica particles including those adsorbed on the surface of the larger ceramic particles, the equivalent of an internal pressure is chemically induced and uniformly draws all particles together.

The ceramic green bodies prepared by freeze gelation are shown in Fig. 3. The shrinkage rate of green body is $0.6 \%$ in the forming and drying process, which is much less as compared with up to $20 \%$ for other processes such as slip casting or gel-casting [3,4], and there are no warpage and cracking. The inner stress generated by shrinkage of green body in the forming and drying process can be inherited in the sintered body to further deteriorate the properties of the ceramics. Since the green body prepared by freeze gelation has little shrinkage and no warpage and cracking in the forming and drying process, inner stress can be negligible in green body, and freeze gelation has great potential as a method for the preparation of near-net size shape ceramic matrix composites. Therefore, freeze gelation is a highly effective ceramic forming method and offers many advantages over conventional ceramic preparation techniques (sol-gel, freeze casting, slip casting and gel-casting, etc.).

The analysis of the micro-CT picture of $\mathrm{Si}_{3} \mathrm{~N}_{4} / \mathrm{BAS}$ composites indicates that there is no obvious defect in the internal structure of the prepared composites. The XRD pattern of $\mathrm{Si}_{3} \mathrm{~N}_{4} / \mathrm{BAS}$ composites (see Fig. 4) indicates that BAS is completely formed by sintering

\section{Conclusions}

We demonstrated an effective approach to prepare $\mathrm{Si}_{3} \mathrm{~N}_{4} / \mathrm{BAS}$ composites by silica sol freeze gelation. In the process of freeze gelation, the particulate silica sol was gelated by freezing, not by altering the sol $\mathrm{pH}$, to solidify ceramic slurry. The added barium oxide and alumina absorbed silica in sol to form the $\mathrm{BaO}-\mathrm{Al}_{2} \mathrm{O}_{3}-$ $2 \mathrm{SiO}_{2}$ system which was used as sintering aid for nitride silicon, and $\mathrm{Si}_{3} \mathrm{~N}_{4}$ /BAS glass ceramic matrix composites were formed by sintering. The cracking and warpage of dried green body were entirely avoided, the shrinkage rate of dried green body was $0.6 \%$, and the flexural strength, work of fracture and density of sintered body were $342 \mathrm{MPa}, 181 \mathrm{~J} / \mathrm{m}^{2}$ and $3.0 \mathrm{~g} / \mathrm{cm}^{3}$, respectively.

\section{References}

[1] Yu JL, Wang HJ, Zhang J. J Sol-Gel Sci Technol 2010;53:515-23.

[2] Wang B, Yang J. J Mater Sci 2009:44:1351-6.

[3] Michael J, Statham B. Eng. economic manufacture of freeze-cast ceramic substrate shapes for the spray-forming process. (Dissertation). United Kingdom: Bath university; 1998.

[4] Joyce L. Freeze casting-a modified sol-gel process. (Dissertation). United Kingdom: Bath university; 1994.

[5] Ronald J, Raymond T. United States Patent no US 20100167020; 2010 (July 1).

[6] Martin O, Ronald J. Ceramic products. United States Patent no US 5811171; 1998 (Sep 22). 